\title{
Una égloga neolatina entre los manuscritos de los hermanos Seripando*
}

\author{
EUGENIA FOSALBA \& ENRIC MALLORQUÍ-RUSCALLEDA \\ Universitat de Girona \\ California State University-Fullerton
}

'There had been an interval of almost a century after Petrarch's followers had played his kind of bucolic to its bitterest end before the genre recovered; it was not until the 1460's that the breath of the gentler humanism of Renaissance brought it back to life, and it revived in a mutated form'. ${ }^{1}$ Con estas palabras se refería Helen Cooper al paso de la bucólica del medievo a la del renacimiento: la clave de esta mutación radicaba en el redescubrimiento de Virgilio; no se trataba tanto del Virgilio profeta o el moralista, como tampoco del místico o el alegorista arcano, sino del artista, del poeta inigualable. Tampoco es que se negara a sus Bucólicas los posibles ecos políticos, las profecías o su inclinación servil al panegírico. Solo que ahora los posibles significados dejaban de estar tan en la penumbra del revestimiento bucólico, pues este había dejado de percibirse como una cáscara vacía. Ni las raíces medievales de la égloga quedaron borradas de un plumazo a favor de un clasicismo más puro, ni las nuevas creaciones se limitaron a los cauces estrictamente intelectuales que Petrarca había impuesto al género. La lectura de las églogas virgilianas, solo guiada en el medievo por la luz vacilante de sus comentaristas, se ve ahora iluminada por acercamientos renovadores de la égloga clásica.

Cristoforo Landino marca en este sentido un claro punto de inflexión: el posible trasfondo de verdad, o mejor, el conato de verdad, a que puede aludir el carácter alegórico de la égloga, es una suerte de punto de fuga, un enigma inherente al género que lejos de rebajarlo le ayuda a ganar altura: en el

* Introducción de Eugenia Fosalba; texto editado y traducido por Enric MallorquíRuscalleda. Este artículo es parte del proyecto FFI2015-65093-P: Garcilaso en Italia. Estancia en Nápoles (I) (2016-2019) del Ministerio de Ciencia e Innovación.

1 Helen Cooper, Pastoral: Mediaeval into Renaissance (Ipswich: Brewer/Totowa: Rowman \& Littlefield, 1977), 107. 
proemio a su comento, Landino destacaba la excelencia del bucolismo de Virgilio, así como su capacidad de perfeccionarlo frente a Teócrito, su principal fuente de imitación; género al que conseguía aportar más elevación gracias a recursos de su propia invención: por eso, sin desprenderse del personaje rústico, consideraba Landino que las bucólicas virgilianas escondían una sensibilidad mucho más alta bajo esa otra capa menos elevada, desarrollando la obra en dos niveles, al dedicarse tanto al tema externo cuanto al escondido; una duplicidad solo propia de la verdadera poesía. ${ }^{2}$

La visión de Virgilio como el mejor de los poetas ofrecida por Landino en su comentario a la Eneida (1462-1463), y poco después a las églogas (1468), se completó más tarde con otros acercamientos más técnicos a la obra del mantuano, como el de Giovanni Pontano en su Actius (1499), en donde se estudiaban las elecciones léxicas de Virgilio, no ya de acuerdo a su significado (como sucede en los comentarios de Mario Servio Honorato y Elio Donato) sino a sus cualidades sonoras. Es decir, como María José Vega ha recordado, Pontano rechazaba la aproximación semántica o gramatical 'a favor de una aproximación elocutiva destinada a rendir la especificidad poética del texto'. ${ }^{3}$ Sin embargo, Pontano no aducía ejemplos de las Bucólicas en su exposición de la excelencia técnica de la poesía virgiliana, pues todas las citas virgilianas de su Actius se referían a las Geórgicas o a la Eneida. Solo más tarde, el bagaje pontaniano acerca de las cualidades sonoras de la poesía de Virgilio, heredado de la retórica hermogénica actualizada por Jorge de Trebisonda, llegaría a poéticas más comprehensivas como las de Antonio Minturno y, ya pasado el medio siglo, de Giulio Cesare Scaligero y Giovanni Antonio Viperano, en las que la égloga obtenía, esta vez sí, un lugar privilegiado. Pero en modo alguno podría decirse que Pontano no tuviera presente el género, pues lo puso en práctica en repetidas ocasiones en sus propias Eclogae, además de erigirse en maestro del gran autor bucólico latino y vulgar de todos los tiempos que fue Iacopo Sannazaro, de quien tomó el nombre el diálogo antes mencionado, pues Actius Syncerus era su apelativo académico, derivado de 'acta', costa (napolitana), que el autor convirtió en paisaje de sus propias églogas piscatorias.

2 'Quod quidem cum praestiterit ac per omnes numeros ita absolverit, ut ei quem sibi imitandum proposuerat nusquam cedat, tamen, quod poetarum est, eodem figmento maiora quaedam contegit: ut quamvis a persona pastorali non discedat, tamen alium sensum longe excellentiorem sub illo vulgari abscondit, ut opus duplici argumento et illi qui in promptu est inserviat et illum qui latet perficiat: quam rem siqui sunt qui vitio illi vertant, ii quid proprium poetarum sit ignorare convincentur' (Praefatio in Virgilio, ed. Roberto Cardini, en La critica del Landino [Firenze: Sansoni Editore, 1973], 309-26 [pp. 313-14]).

3 María José Vega, El secreto artificio: maronolatría y tradición pontaniana en la poética del renacimiento (Cáceres: Univ. de Extremadura, 1992), 50. 
Por lo demás, la publicación de las preceptivas que dedicaron buena parte de sus consideraciones a analizar el fenómeno eglógico fue tardía en el XVI: la de Minturno permaneció largos años manuscrita hasta que por fin se dio a conocer al gran público, animado su autor por Girolamo Ruscelli (1559), y muy poco después llegó a las prensas la de Escalígero (1561), así como la de Viperano (1579), estos dos últimos compusieron las suyas casi simultáneamente y de forma independiente, según María Luisa Picklesimer. ${ }^{4}$ El De poeta (1559) de Minturno tiene la virtud, como también su Arte poetica de 1564, de recrear la Nápoles del pasado y la del presente, remitiendo a la ascendencia intelectual de la segunda sobre la primera. Así, Minturno, como personaje del diálogo y también como autor, se erige en intermediario de la tradición humanística de raíz pontaniana, de la misma manera que ilustrará el paso de la latinidad a la poética vulgar. ${ }^{5}$ Sus interlocutores, en la ficción del diálogo sobre poética latina, son miembros de la academia pontaniana y humanistas napolitanos, y la conversación se desarrolla teniendo muy presentes los lazos de amistad que unieron a Sannazaro, Pietro Summonte y Girolamo Carbone. Tras la alabanza de Pontano y Sannazaro en el prólogo del De Poeta, Minturno recrea las reuniones durante la primavera de 1526 en Villa Mergellina, cuya torre tenía una vista privilegiada sobre en el golfo de Nápoles; en estas veladas se presenta a Actius Syncerus exponiendo lecciones de poética a sus contertulios. Las más recientes investigaciones sugieren que el joven Minturno no asistió a las reuniones de Villa Mergellina, reservada a los grandes humanistas y jóvenes patricios, si bien en el mismo período participó (y con papel protagonista) en alguna otra tertulia napolitana alternativa acerca de poética en vulgar, a la que se hace alusión tangencial en el De Poeta. Parece demostrado también que Minturno conoció el contenido de las tertulias auspiciadas por Summonte y Sannazaro gracias a su amistad con Lucio Camillo Scorziano y Andrea Cossa (asistentes, como Gesualdo, a la dedicada a Petrarca), y que el De Poeta se escribió entre 1525 y 1533, en un contexto próximo a las Prose della volgar lingua de Pietro Bembo, ante las que hay una toma de postura. ${ }^{6}$

4 María Luisa Picklesimer, 'Teoría de la bucólica en el De poetica de Viperano', en Retórica, poética y géneros literarios, ed. José A. Sánchez Marín \& María Nieves Muñoz Martín (Granada: Univ. de Granada, 2004), 367-86 (p. 368). Picklesimer conjetura que Minturno escribió su poética latina por las mismas fechas que Scaligero y Viperano, a su vez sin conocerlas.

5 Vega, El secreto artificio, 216.

6 Para la argumentación histórica que avala este temprana redacción del De Poeta, véase Eugenia Fosalba, 'Tracce di una precoce composizione (ca. 1525-1533) del De Poeta di Minturno: a proposito della sua possibile influenza su Garcilaso de la Vega', Critica Letteraria, 173 (2016), 627-50. Acerca de de la influencia literaria en Garcilaso en el contexto de las Prose de Bembo, véase Eugenia Fosalba, 'Ecos de la preceptiva minturniana en las 
Como fuere, la atención que dedicaron estos tres preceptistas a la égloga, aunque llegara a la imprenta con retraso, fue, por fin, pormenorizada, e incluso Viperano se permitió expresar su sorpresa acerca del motivo por que no se hubiera dado antes: cuál podía ser la causa de que los antiguos no hicieran mención alguna al poema bucólico si éste tenía su propia esencia, diferenciada de los demás géneros, se preguntaba extrañado. Y sugería que quizá supusieron que podía considerarse incluido en el concepto de comedia, o que carecía del mínimo artificio y que por tanto podía deducirse de los preceptos que se adjudicaban a otros géneros. $^{7}$

Consciente de esta carencia, Minturno retomó el hilo de algunos de los razonamientos clave de Landino: en su texto advertía que en siete de sus églogas Virgilio empleó un estilo simple sin que ello fuera obstáculo para que el retrato de los pastores se refiriera oblicuamente a otros asuntos mayores; y que eso embellecía su obra, que en sí misma era simple y ligera, porque mientras por un lado nunca quitaba el velo que pertenecía al personaje que retrataba, por otro lado las partes subyacentes aportaban una técnica más elegante, pues se hallaban elaboradas ingeniosamente de forma que los velos internos permanecían escondidos tras los velos externos del poema. Y recordaba, entre otras cosas, los momentos en que Virgilio se dedicaba a la alabanza de Augusto y Asinio Polión, o a lamentar la muerte de César, a la pérdida de sus tierras, o a la alegría de recuperarlas, aunque pareciera que estaba haciendo otra cosa. Esta era la verdadera costumbre de los poetas, afirmaba Minturno por boca de Sannazaro: esconder la verdad en falsedades, y envolver las cuestiones graves en otras lúdicas. Y añadía, además, que Virgilio fue el primero en mostrar la posibilidad de que la poesía bucólica incluyera cosas profundamente ajenas al medio pastoril, de tal forma que no parecieran disminuidas (por asociación con su 'bajo' estilo). Minturno también ponía de manifiesto su admiración por la capacidad de los poetas de adecuarse a la sencillez de sus personajes en la bucólica, y en este sentido consideraba que fue Teócrito quien demostró lo puras y simples que eran las palabras y las ideas que se requerían, y lo hizo con tanto éxito que se creía que lo consiguió gracias al dialecto dórico. Sin embargo, objetaba, si Virgilio no persiguió este mismo estilo frugal debía

églogas de Garcilaso', en La égloga renacentista en el reino de Nápoles, ed. Eugenia Fosalba \& Gáldrick de la Torre, Bulletin Hispanique, 119:2 (2017), en prensa.

7 'Hoc uero etiam mirum uidetur, bucolicum poëma fuisse ab illis silentio praetermissum; quod est quidem ex imitatione et carmine, quodque uerisimile est omnium esse uetustissimum; cum ex antiquissimo uiuendi more productum sit, qui pastoritius et agrestis fuit. An forte contineri notione Comoedie putauerunt? Quod nomen late adeo patet, ut omnes fabulas dramaticas significationis suae ambitu comprehendat [...] Sed cur nullam omnino mentionem eius fecere, cum a reliquis generibus uim suam distincta habeat? An quia leui artificio indigeat, et possit ex aliorum praeceptis cognosci?' (Giovanni Antonio Viperano, De Poëtica libri tres [Antuerpiae: Ex officina Christophori Plantini, 1579], 27-28; citado por Picklesimer, 'Teoría de la bucólica', 370). 
atribuirse a su divina majestad y su sentido romano de la gravedad. En cualquier caso, concluía, ofreció una admirable demostración de su capacidad en el manejo de lo simple y lo bajo así como de la admiración que se puede conseguir incluso en el más insignificante de los géneros. Y a continuación el De Poeta ofrecía ejemplos extraídos y comentados de las Bucólicas acerca de las figuras del estilo, en el uso de la comparación, la analogía, etc. ${ }^{8}$

No podemos olvidar que cuando Minturno publicaba estos comentarios acerca de la bucólica virgiliana, poniéndola como ejemplo más excelso del género en todos los tiempos, las muestras de églogas neolatinas habían proliferado en suelo italiano ya desde finales del XV (Guarino Veronese, Tito Vespasiano Strozzi, Matteo Maria Boiardo y Gaspar de Trimbochi en Ferrara; Battista Fiera, Vincenzo Barsi, Baldassare Castiglione y Battista Spagnoli en Mantua; Giovanni Stefano Cotta, Bonino Mombrizzio en Milán; Naldo Naldi y Amerigo Corsini en Florencia; Francesco Patrizi, Paracleto Cornetano, Andrea Fulvio en la Roma papal; y en Nápoles, Pomponio Gaurico, Girolamo Angeriano, Giano Anisio, Pontano y Sannazaro, éstos últimos con émulos en el norte de Italia tan destacados como Marcantonio Flaminio, Andrea Navagero y Girolamo Fracastoro); por no mencionar las vulgarizaciones del XV recogidas en Florencia por Miscomini en 1481, así como las incansables imitaciones también en vulgar de la Arcadia sannazariana, ni la tradición de las églogas destinadas a la representación que tuvieron como punto de partida el Orfeo (1478-1483) de Angelo Poliziano. En los primeros años del siglo XVI se dio también el contagio imparable de la moda bucólica al resto de Europa, convirtiéndose así el fenómeno pastoril en una auténtica epidemia. Todo era susceptible de convertirse en temática pastoril; incluso la terrible enfermedad de la sífilis pudo disfrazarse de pastor bajo la pluma del prestigioso humanista y científico veronés Fracastoro.

8 'Ac septem a Virgilio Eclogas (sic ille appellat quae Theocritus Idyllia) ita scripta reperies. Nisi reprehendendum putas, quod fabula pastorali maiora quaedam contexerit. Et quae ut dicant, pastores inducuntur, ad alia intellexerit esse transferenda. Mihi uero ille uel hoc praecipue mirabilis uidetur, quod cum agrestes humilesque personas quae nihil non rusticum simplexque loquantur, introducat, lusu illo grauia quaedam abdite comprehendit, opusque per se nudum ac tenue sic exornat, ut cum exteriorem habitum et personae conuenientem nunque exornat, interiorem induat politiorem in modum, atque cum in id quod apparet, incumbat id quod latet, probe conficiat. Augustum enim, Pollionemque laudat, Caesaris interitum deplorat, queritur se amisisse agrum, recepisse Laetatur, cum aliud agere uideatur. Is poetarum sanè mos est, ut fictis uera occulte, ludo seria complectantur. [...] Itaque primus docuit quae a Bucolica ratione putantur abhorrere, quam probe attingi possint, quo minus dedecere uideantur. Nec uero eiusmodi quidquam sine praemunitione aggreditur' (Antonius Sebastianus Minturnus, Antonii Sebastianii Minturni de Poeta Libri Sex [Venetiis: apud Franciscum Rampazetum, 1559], 162-63). 
Alejandro Coroleu ha analizado recientemente la difusión de la bucólica neolatina a través de la imprenta, en los años 1485-1535, estableciendo varias calas en el vasto océano de muestras eglógicas que ofrecen esos cincuenta años de transición al renacimiento: su estudio concluye que el interés en los círculos reformistas se centra en buena medida en las bucólicas de Petrarca y Baptista Mantuanus (Battista Spagnoli), por las críticas del primero a la decadente corte papal de Aviñón y las del segundo a la corrupción de la Curia papal. Eso explicaría la gran aceptación de las ediciones con comentarios a las bucólicas de Petrarca, como los del célebre humanista, editor y tipógrafo belga, Badio Ascensio, o de Juan Luis Vives, que, podríamos añadir aquí, ya se habían acercado a las églogas del propio Virgilio cargando las tintas pedagógicas y morales, en el caso de Vives hasta extremos insospechables. ${ }^{9}$ Por otro lado, los acercamientos moralizadores tienen su explicación, como recuerda el mismo Coroleu, en el lugar asignado a este corpus poético en el curriculum studiorum de la época. El interés se centraba en la sustitución de las bucólicas de Virgilio por otras muestras menos peligrosas u obscenas; los profesores universitarios verían con buenos ojos un corpus poético libre del veneno pagano que amenazaba con intoxicar las mentes de los estudiantes. Se trata, así, de un corpus literario impulsado por la censura moral y religiosa, que 'written in the style of the ancients, [it] was adapted to a Christian ethos' ${ }^{10}$ Hay, por tanto, tras estos intentos y su éxito en las prensas, un acusado interés pedagógico por textos bucólicos neolatinos que no resulten perniciosos y por el contrario sean edificantes en los jóvenes estudiantes. Y fue probablemente la lectura y el trabajo en las aulas con las ediciones comentadas del Bucolicum carmen (1349-1367) de Petrarca y de la Adolescentia (1513) de Baptista Mantuanus, las que espolearon las imitaciones nacionales, especialmente en el primer cuarto del

9 En 1539 Juan Luis Vives publica unos comentarios a las bucólicas en las que sus observaciones tienen un férreo sentido translaticio de índole moral. En el prólogo a sus escolios, Vives se desvincula de la limitada alegoría de Servio e incluso llegará a reconocer que ha llegado a atribuir a los versos del mantuano alguna alegoría en la que su autor jamás había pensado. Véase, Juan Luis Vives, Interpretación de las 'Bucólicas' de Virgilio principalmente alegórica, ed. José Esteve Forriol (València: Ajuntament de València, 1997), 35. La edición parisina de Badio Ascensio de la obra virgiliana en 1500-1501 puede haber constituido una autorización a las versiones morales de las églogas del mantuano, pues éstas van precedidas por una epístola dirigida al jurista Anselme de Brieure en la que el humanista y tipógrafo belga señala las cualidades edificantes de las bucólicas. No extraña que en la relación de ediciones ascensianas de la obra de Virgilio haya una veneciana de 1566 en que aparecen yuxtapuestos los comentarios de ambos humanistas, corroborándose así dicha afinidad. Para las ediciones de Badio Ascensio, véase Philippe Renouard, Bibliographie des impressions et des oeuvres de José Badius Ascensius imprimeur et humaniste (1462-1535) (Paris: Paul et fils et Guillemin, 1908), 360-83. Véase también, Alice Hulubei, L'Eglogue en France au XVI İme siècle: époque des valois (1515-1589) (Paris: Droz, 1938).

10 Alejandro Coroleu, 'Printing and Reading Italian Neo-Latin Bucolic Poetry in Early Modern Europe', Grazer Beiträge, 27 (2010), 53-69 (p. 67). 
siglo XVI. ${ }^{11}$ Poco después de estas fechas, las églogas de Petrarca, Antonio Geraldini, Baptista Mantuanus y Fausto Andrelini dejaron de ser del gusto del público, sustituidas por las de Sannazaro, Marco Girolamo Vida, y Fracastoro, más plenamente renacentistas. ${ }^{12}$ Scaligero, gran abanderado de Virgilio, da fe de este cambio en el gusto, pues abomina de Baptista Spagnolo y su latín poco depurado, alejado de las sutilezas de otros humanistas más refinados $;{ }^{13}$ en efecto, poco tiene que ver el vitalismo, el realismo a veces chocarrero y el humor de Spagnoli, con la delicadeza de otro poeta, a su vez mantuano, como Castiglione, en su magnífica égloga elegíaca Alcon ('Longe excellentissimus in poesi spiritus Balthassaris Castilionei nihil dulcius Elegia, nihil elegantius, tersius, lepidius'). ${ }^{14}$

Es tal la variedad de producción eglógica neolatina publicada en el siglo XVI, que Leonard Grant se vio en la necesidad de reducir su vasta heterogeneidad a una clasificación tripartita: hay tres tipos fundamentales de églogas. 1) La pastoral puramente clasicista, a la que denomina 'artpastoral': en ella, el poeta intenta componer una obra inspirada en la clásica, pero independiente desde el punto de vista creativo (algo que solo los poetas de primera fila consiguieron; un buen ejemplo sería la elegía eglógica Alcon de Castiglione). 2) La pastoral de circunstancias (o 'New uses of pastoral'): en donde la égloga es solo un medio para celebrar la grandeza o execrar el vicio, satirizar la estupidez y fustigar la incompetencia, celebrar victorias o lamentar desastres (aquí también entrarían las églogas que generó la celebración de la Navidad, que luego llevaría al desarrollo de pastorales basadas en temas del Antiguo Testamento, y más tarde a secuencias completas de églogas devocionales y litúrgicas dedicadas a la Virgen María). Cualquier tema podía convertirse en temática pastoril: la boda de un amigo o un poema didáctico sobre la crianza de los perros (aquí entraría Alcon, sive de cura canum venaticorum, de Fracastoro). Por último, 3) 'New forms of pastoral', que están a medio camino entre las 'art-pastoral' y los 'new uses of pastoral'; es decir, a medio camino entre las églogas clasicistas y las pastorales neolatinas modernas: son églogas que tienen como protagonistas a pescadores, cazadores, navegantes, jardineros, vinateros, etc. (este sería el caso de las piscatorias de Sannazaro). ${ }^{15}$

11 Coroleu, 'Printing and Reading', 68. Sobre la importancia de la Adolescentia de Baptista Mantuanus en la cultura literaria latina del Renacimiento, véase el trabajo de Mariano Madrid ('Poesía bucólica en los estudios de latinidad del sur de la Península: la Adolescentia de Baptista Mantuanus') publicado en este volumen.

12 Coroleu, 'Printing and Reading', 69.

13 Iulius Caesar Scaliger, Poetices Libri Septem (Lugduni: apud Antonium Vincentium, 1561), VI, 4, 304.

14 Scaliger, Poetices, VI, 4, 307.

15 W. Leonard Grant, Neolatin Literature and the Pastoral (Chapel Hill: Univ. of North Carolina Press, 1965). 
Ahora bien, hay églogas que han escapado hasta ahora de la atención de la crítica y que no han ingresado todavía en la historia de la literatura: permanecen manuscritas y sin editar, las hay en griego y otras en latín, algunas anónimas, otras firmadas con seudónimos de autores desconocidos, como la composición neolatina que Enric Mallorquí transcribe y traduce en el apéndice a este artículo. Me refiero ahora a una pequeña parte de la producción poética que se conserva en el legado napolitano de los hermanos Antonio y Girolamo Seripando, documentación que hoy se conserva en la Biblioteca Nacional de Nápoles, y que recoge, no sólo gran parte de la correspondencia de ambos, sino un valioso conjunto de composiciones poéticas de variada autoría y factura, la mayoría escrita en latín, otras en griego, y otras cuantas en italiano. La égloga que hoy rescatamos del olvido se presenta, así, mezclada en un conjunto más amplio de epístolas, obras poéticas, fragmentos de opúsculos en prosa, hasta ahora solo parcialmente estudiados y editados, y cuyo contexto queda, salvo por las valiosas aportaciones de Michele Fuiano en 1973, pendiente de un estudio exhaustivo. ${ }^{16}$ Dos copias de las composiciones neolatinas de Garcilaso se conservan precisamente entre esa documentación privada, además de la última carta, autógrafa, dirigida a su íntimo amigo, Girolamo Seripando, a quien nuestro poeta escribió desde Savigliano pocas semanas antes de morir. El hecho de que las copias de dos de las composiciones neolatinas de Garcilaso estén recogidas entre esa documentación apunta a la pertenencia de nuestro poeta al mismo círculo de poetas y humanistas postpontanianos cuyas cartas y obras quedan consignadas ahí, todas del entorno de los hermanos Seripando en Nápoles. Por otro lado, resulta altamente significativo que en la oda de Garcilaso dirigida a Antonio Tilesio y recogida entre dicha documentación, sea el mismo poeta quien nos explique que ese es el círculo que lo acogió a su llegada a Nápoles. Curiosamente, cuando Ortensio Lando escribe su diálogo Cicero relegatus \& Cicero revocatus, dialogi festivissimi, publicado en Milán en 1534, ambienta la primera parte de su obra en el convento de San Giovanni a Carbonara, del que Lando formó parte hasta antes de la muerte de Antonio Seripando en 1531. Es esta la causa de que en su tratado, lleno de dejos irónicos acerca del ciceronianismo y anticiceronianismo a ultranza, aporte, como ejemplo de ciceronianos, si bien no estrechos de miras, a los frailes con quienes convivió en calidad de fray Hiremias: por supuesto, Girolamo Seripando y su hermano Antonio. Junto a ambos hermanos,

16 Nuestra égloga se encuentra en el Ms. XIII, AA63, ff. 54-55 de la Biblioteca Nacional del Nápoles. Hay otra copia de dicha composición en el Ms. V E 53, $57^{\mathrm{r}}-58^{\mathrm{v}}$, de la misma Biblioteca. Véanse las trascripciones de algunas de las obras que recoge dicha signatura en Antonio Altamura, L'umanesimo nel mezzogiorno d'Italia: storia, bibliografie e testi inediti (Napoli: Bibliopolis, 1941); Michele Fuiano, Insegnamento e cultura a Napoli nel Rinascimento, (Napoli: Libreria Scientifica Editrice, 1969); e Italo Gallo en su edición de Pomponio Gaurico, Inno greco a Fabrizio Brancia (Napoli: Arte Tipografica, 1998). 
intervienen en el diálogo los dos amigos de Garcilaso mencionados en su oda a Tilesio: Placido de Sangro y Mario Galeota. Placido de Sangro fue gran amigo de Antonio y después de Gerónimo. Los papeles de ambos hermanos contienen asimismo numerosas cartas de Placido de Sangro. ${ }^{17}$ Parece que Antonio fue a su vez poeta, como parece avalar el hecho de que se conserven composiciones con la anotación al margen, 'manu et opera Antonii Seripandi'; no hay que olvidar que Aulo Giano Parrasio llamó a Antonio 'alumno de las musas' ('alumnusque Musarum'). ${ }^{18}$

Antonio, mayor que Géronimo, fue muy plausiblemente quien, con su amor por la filología y su generosidad de ánimo, su hondo sentido de la amistad, hizo posible el grupo. La figura de Antonio Seripando, siempre en segundo plano, siempre receptivo, cuidadoso compilador de misivas y de obras del círculo napolitano, así como de humanistas amigos no necesariamente afincados en la ciudad partenopea (Antonio es el heredero de la magnífica biblioteca de Parrasio, que después pasaría a manos de su hermano), se perfila como el verdadero secretario, durante largos años, de los círculos potspontanianos en la Nápoles aragonesa. Fuiano sigue, a través de las cartas, la dulce amistad que Antonio mantuvo con el propio Sannazaro, quien le dedicó varias misivas conservadas entre esta misma documentación, en algunas de las cuales le pedía consejo estilístico sobre el De partu Virginis, como a su vez había solicitado a Iacopo Sadoleto y Antonio Tebaldeo. Antonio debía buena parte de su formación a Luigi Pulci, de quien había sido discípulo, y por supuesto, está en el trasfondo de las discusiones filosóficas y literarias del grupo de San Giovanni de Carbonara el recuerdo de los días de Egidio de Viterbo, quien se adscribía a la fascinación agustina por el significado alegórico y secreto tanto de la poesía clásica como de las Escrituras: en el campo literario esto suponía la antigua idea de la poesía como disfraz de una sabiduría más alta (presente en la tradición de las defensas de la poesía que Landino y después Minturno aplican a la égloga). Como es bien sabido, aunque el gran propagador de la idea de la divina verdad oculta bajo el velo fue de Dionisio de Pseudo-Areopagita, esta recibió gran ímpetu con la publicación de la Geneologie deorum gentilium libri de Boccaccio, que

17 Junto a composiciones de Antonio Seripando (por confirmar), Decio Apranio, Lepiro, Pomponio Gaurico, Giovanni Andrea, Cino da Pistoia, Vincentus Galeota, Hieronimus Carbo, P. Feltri, M. A. Casanova, Salvio Capelletti, Crispoldo Crispoldi, Seraphinus Griphonus Reatinus, entre otros. Otras composiciones aparecen dedicadas a Antonio y Gerónimo Seripando, Parrasio (quizá de Gerónimo Seripando; es conjetura de Paul Oskar Kristeller, Iter Italicum: accedunt alia itinera. A Finding List of Uncatalogued or Incompletely Catalogued Humanistic Manuscripts of the Renaissance in Italian and Other Libraries, 6 vols [Leiden: Brill, 1983-1997], II, 549), Jacobus Sadoleto, Angelus Ubaldus y Franc. Lombardus.

18 Aulo Giano Parrasio, Auli Jani Parrhasii Consentini quaesita per epistolam ex recensione Henr. Stephani; in Neapolitana hac editione acceserunt quaedam ex Parrhasii m. ss. excerpta; cum auctoris vita conscripta ab Xaverio Matthaei (Neapoli: Typographis Simoniis fratribus, 1771), 250-51. 
tenía el expreso propósito de descubrir lo que los antiguos habían escondido 'sub ridiculo cortice fabularum'. ${ }^{19}$ Sobre la relación intelectual de Pontano y Egidio queda el testimonio del diálogo que Pontano tituló con su nombre, y en donde se reproducía uno de sus sermones. Se conserva, además, una carta que Girolamo Borgia envió a Egidio, del 3 de diciembre de 1505, en que le pide que le envíe una copia de su égloga 'De Christi ortu'. ${ }^{20}$

Girolamo Seripando, que sobrevivió largos años a su hermano, había sido en sus comienzos protegido de Egidio de Viterbo, a quien tuvo presente como maestro hasta el fin de sus días, y parece que heredó de él el abandono del enclaustramiento y la apertura de su espíritu tolerante, así como la propensión a la amistad, que también había practicado su hermano y que resultó tan fructífera en el desarrollo literario de la elite intelectual de San Giovanni a Carbonara. Es Pontano quien nos recuerda la costumbre, adquirida en compañía de Egidio de Viterbo, de dialogar paseando por los jardines del convento, en compañía de otros humanistas como el propio Pontano, el Cariteo, o Carbone, y parece lo más probable que se reprodujera años más tarde, teniendo como centro, entonces, a Girolamo Seripando, cuando éste ya había sustituido a su hermano en su papel de galvanizador social del grupo.

Muchos de los poemas consignados en los papeles de los hermanos Seripando, copiados algunos de la mano de Antonio, son, así, anteriores a la estancia de Garcilaso en Nápoles, o bien posteriores (otros contemporáneos, bien es cierto). ${ }^{21}$ De entre ellos se conserva la égloga que transcribimos en apéndice, dedicada al príncipe Traiano Cabanillo, conde de Tria y de Montella (1479-1528), y al duque de Acquaviva, del que no se menciona el nombre, pero hay que suponer que se trata de Andrea Matteo Acquaviva (¿1458?-1529).

El Príncipe Troiano Cabanillo recibió una esmerada educación humanista bajo la tutela del rey Ferrante, y muy pronto entró a formar parte de la élite intelectual pontaniana como poeta diletante. Con el tiempo se convertiría en un generoso mecenas que acogería en su palacio de Montella a una corte de literatos, de entre los que se cuentan Sannazaro y Anisio, sus protegidos. Este último le dedicó un larguísimo poema que abre su libro de Sátiras

19 John W. O'Malley, Giles of Viterbo on Church and Reform (Leiden: Brill, 1968), 56.

20 Napoli V.F.20, fols $296^{\mathrm{v}}-97^{\mathrm{r}}$. La égloga se encuentra en Ang. Lat. 1001, fols $39^{\mathrm{r}}-42^{\mathrm{v}}$. En el mismo códice hay otras dos églogas, fols $36^{\mathrm{r}}-8^{\mathrm{v}}, 42^{\mathrm{v}}-4^{\mathrm{v}}$, y una carta de Egidio a Borgia, $\sin$ fecha, $246^{\mathrm{r}}-47^{\mathrm{r}}$. También se publicaron, por Francesco Trucchi, seis madrigales atribuidos a Egidio y dedicados a Vittoria Colonna, en Poesie italiane inedite di dugento autori dall'origine della lingua infino al secolo decimosettimo, ed. Francesco Trucchi, 4 vols (Prato: Per R. Guasti, 1846-1847), III, 124-29; citado por O’Malley, Giles of Viterbo, 9, 56.

21 Contemporáneo a la estancia de Garcilaso en Nápoles es el epigrama latino dedicado a la muerte de Ariosto (m. 1533), por ejemplo (Ms. XIII AA 63, f. 65 y ss.). Véase Eugenia Fosalba, 'Más sobre la estancia de Garcilaso en Nápoles: epigramas funerales a la muerte de Ariosto', Rinascimento meridionale. Napoli e il Viceré Pedro de Toledo (1532-1553), dir. Encarnación Sánchez García (Napoli: Tulio Pironti, 2016), 387-408. 
(publicado en 1532 pero elaborado muchos años antes). Troiano Cavaniglia y Andrea Matteo Acquaviva (el segundo dedicatario, hermano del docto Belisario, también miembro muy activo de la academia de Pontano) compartieron además de una estrecha amistad, la alcurnia, la milicia y una muy notable inclinación por las letras, y por el mecenazgo (más activo en el primero que en el segundo), hasta el punto de que Sannazaro dedicó su Salices a Troiano y Paolo Giovio dedicó a Andrea Matteo todo un capítulo de los Elogi dei Letterati Illustri. ${ }^{22}$

La égloga responde por su orientación eminentemente panegírica al segundo tipo de égloga neolatina establecido por Grant: 'new uses of pastoral'. El lugar de composición es, como se ha visto, a todas luces Nápoles: entonada por los pastores que dan título a la obra, con nombres de cariz eminentemente clásico (Mosticus, Egenus et Alphesiboeus), debió componerse en el primer cuarto de siglo; no sabemos si Egenus puede responder a la máscara de Egidio de Viterbo, quien permaneció en San Giovanni a Carbonara entre 1499 y 1501; podría resultar dudoso, pues egenus, con sus resonancias de pobreza, no parece adjudicable a un agustino de peso, como era Egidio, aunque bien es cierto que en aquellas fechas todavía era joven y le quedaba mucha carrera por delante; el nombre hace referencia, además, a una pobreza material que contrasta frente al personaje poco halagüeño del opulento Plusius, lo que termina dando más brillo a la riqueza interior (moral e intelectual) de Egenus. Los nobles a quienes se dedica la égloga y a quienes se cita (Cabanilius y Acquavivus) se presentan como dos miembros más del grupo de pastores y elocuentes poetas (se supone de la escuela pontaniana), en abierto contraste con el rico Plusius, ajeno a cualquier inquietud literaria, lo que impedirá que su nombre perdure gracias a la fama de sus obras, mientras que Cabanilius y Acquavivus, a quienes se agradece la protección, el regalo de piezas de ganado, y sobre todo, la inspiración, vivirán y siempre serán recordados. El rico inculto, además de ser un tópico de la poesía pastoral, podría ser una referencia a los nuevos ricos del período postaragonés, quienes se pusieron rápidamente de parte del vencedor (primero francés, después español) traicionando la dignidad que la casta noble napolitana exigía (e incluso la referencia a la movilidad de la fortuna podría entenderse en este contexto). ${ }^{23}$

22 Paolo Giovio, Elogi degli uomini illustri, ed. Franco Minonzio, trad. Andrea Guasparri \& Franco Minonzio (Torino: Giulio Einaudi Editore, 2006), 213. Sobre el linaje de los Cavaniglia, véase Francesco Scandone, 'I Cavaniglia conti di Troia e di Montella dalla metà del sec. XV alla fine del sec. XVI', Archivio Storico per le Provincie Napoletane, Ser. NS, 9 (1923), 136-218 (pp. 150-89).

23 Agradezco la sugerencia a Claudia Corfiati. Véase, además, su contribución a las églogas de Egidio de Viterbo, 'Note sulla poesia bucolica di Egidio', Egidio di Viterbo, Cardinale agostiniano, tra Roma e l'Europa del Rinascimento, ed. Myriam Chiabò, Rocco Ronzani \& Angelo Maria Vitale (Roma: Roma nel Rinascimento, 2014), 381-402. También, Giovanni Pontano, Aegidius. Dialogo, ed. Francesco Tateo (Roma: Roma nel Rinascimento, 2013). 
En fechas tempranas del siglo XVI, Cavaniglia y Acquaviva debían de disfrutar, en efecto, del apogeo de su vida social e intelectual: de hecho, después de 1505, empieza a manifestarse este mecenazgo, lo que daría una primera indicación cronológica de la pieza que editamos aquí. También hay una clara alusión a Sannazaro, cuando se cita a Attius (Actius Syncerus), que hallaría inspiración para su De Partu Virginis escuchando un sermón de Egidio de Viterbo: en la égloga se tiene al autor de la Arcadia por el más famoso de los pastores de sus sagradas grutas, cuyos cantos, a causa de su excelencia, tienen el poder sobrenatural de silenciar las brisas y calmar las aguas de los ríos ('Attius et vivet sacris notissimis antris / Quo cantante silent aurae fluviique residunt'). Puede que se le recuerde aquí en alusión a su obra bucólica, mezcla de prosa y verso, y también a Salices, el poema dedicado por Sannazaro a Troiano Cabanilla, y entonces la fecha de composición de la presente égloga debería posponerse todavía más (se da, además, la presencia de sauces aquí y allá en la égloga: Egenus, por ejemplo, esperará entre los flexibles sauces y la ribera a que llegue Pan y los sátiros para que escuchen sus canciones: 'Ipse inter lentas salices humilesque genistas / Et Pana et satyros ad carmina nostra vocabo'). Hay, además, algunas sutiles pinceladas de evocación del paisaje idílico que denotan el gusto renacentista por la naturaleza recreada artísticamente, lo que en algún momento acerca esta composición que presentamos seguidamente, a la 'art-pastoral' de la clasificación de Grant, de la que Sannazaro fue maestro. La égloga de Mosticus, Egenus et Alphesiboeus nace, así, en los comienzos de una época floreciente, cuya desaparición Minturno lamentaría amargamente en su De Poeta, ese tratado de preceptiva poética, escrito a modo de diálogo para homenajear y devolver a la vida a aquella elite intelectual napolitana, perdida para siempre tras el asedio de Lautrec y la devastadora peste que trajo consigo (1559 [VI, $434-438]) .{ }^{24}$

$* * * * *$

\section{Criterios de transcripción de la égloga}

- Se ha respetado en lo posible la grafía original, incluyendo las mayúsculas iniciales de cada verso.

- Las abreviaturas se han desarrollado entre paréntesis.

24 Vega, El secreto artificio, 59. Minturno escapó a ella al instalarse en 1528 en Ischia acogido por la Duquesa de Francavilla, al calor del arte de Vittoria Colonna; más tarde, pasó al servicio del virrey de Sicilia, Ettore Pignatello. Solo a la muerte del virrey regresaría a la Calabria, en 1535, y solo años después, en 1541, residiría de nuevo a la ciudad de Nápoles, en donde ya quedaba poco o nada de aquel mundo añorado. 
- Se ha preferido distinguir gráficamente entre $u \mathrm{y} v$, de manera que se han transcrito de acuerdo con el impreso.

- Se ha igualmente respetado la línea de escritura del impreso.

- La 's' mayúscula se ha transcrito como 's' normal, sin más indicación.

- No ha hecho falta desarrollar la nota tironiana, al no aparecer en el impreso.

- Se ha optado por intervenir, aunque lo más mínimo posible, en el documento y, como consecuencia, puntuar ortográficamente con la simple finalidad de facilitar la comprensión. Para ello se ha optado por seguir el sistema actual de puntuación.

- Entre paréntesis cuadrados se han reconstruido los nombres que se omitían al inicio de algunos versos con la finalidad de facilitar la lectura y comprensión del documento.

- Las partes perdidas de las palabras a causa del deterioro del documento se han indicado también entre paréntesis cuadrados. Más concretamente se trata de las palabras iniciales de los seis primeros versos. Como corolario, se ha optado por reconstruir las palabras 'Plusius,' (en dos ocasiones), 'invisor', 'te', 'tempore' y 'Est'.

$$
* * * * *
$$

\title{
Texto
}

\section{Pastores Mosticus, Egenus et Alphesiboeus}

\author{
[Mosticus] \\ [Plusius], ut fama est sylvis, contemptor, Egene, \\ [In]visor(que) tui est: mihi displicet: ille fatetur \\ Satis ignavum inlaudato vivere more. \\ [T]empore tu ne aliquo fortasse iniurius illi. \\ [Pl]usius est fateor tuguri dives et agri \\ [E]st nivei(que) gregis: nivei quo(que) lactis abundans. \\ Ut(que) illi parta est ea copia dii bene norunt. \\ Non calamos inflare leves, non ducere versus \\ Scit miser: et vere miser est, cui tanta peculi \\ Et cura et studium et tantus labor incrementi. \\ At casa quam cervis multo(que) e vimine texit \\ Plusius. Est igni et rapidis obnoxia ventis \\ Perdere(que) illius possunt lata arva procellae \\ Et possunt oculi pecus extenuare nocentes
}


Aut scabies saeva aut diri contagia morbi.

Aut mihi quae poterit saevi inclementia caeli

Deterere ingenium nostram aut delere Camenam.

Mostice, fortunae est vis magna, potentia maior

Virtutis, quae sola suos non fallit amicos.

\section{Mosticus}

Non ego fortunam, virtutem non ego novi

Plusium at ipse scio, nostris qui montibus ingens

Est et praecipuus, digito quem rustica pubes

Monstrat: et ore refert. Hic ingens Plusius ille est

Qui spaciosa tenet Cerealis iugera campi

Non centum potuere boves sulcare quot annis,

Qui(que) arbusta tenet faecundo plena Lyaeo

Lata(que) sylvarum tot pabula glandiferarum

Pomiferos(que) hortos, e vivo fonte rigatos

Umbrant quos platani, quos laeta rosaria cingunt.

Centum habet et magnis pulcros in ovilibus hyrcos,

Centum habet et tauros certantes cornibus at(que)

Mille per errantes pascit cum matribus haedos,

Caseus(que) recens est illi, et copia lactis.

[Egenus]

Ille opibus famuletur inops curisque prematur.

Tutior at mihi paupertas, et conscia recti

Mens bona: paupertas opulentior est mihi: sit fas

Arbore sub patula in sylvis deducere versus.

Ille inter pinus fagosque superbiat inter

Imponatque novas leges et jura colonis

Et quoscumque notet pastores sacra litantes.

Ipse inter lentas salices humilesque genistas

Et Pana et satyros ad carmina nostra vocabo.

Illius in mensa nunquam collocasia desit

Lac et concretum, poma et felicia nunquam.

Serpillum mihi et allia sit redolens et anetum,

Sepibus et late crescens asparagus irtis,

Castaneae molles sint et silvestria mala.

At(que) sitim vitrei mi fontis leniat unda,

Sugerat et dulcem picta inter prata soporem

Garrula vox avium et labentis murmura rivi

Hiis ego contentus calamis contentus et istis.

\section{Mosticus}

Crede mihi tantum Plusio tu cedis Egene

Sylvestris quantum labrusca agrestibus uvis, 
Vitibus at(que) ederae quantum, et filiceta salictis.

Plusius est magnus tandem et per saecula vivet.

Egenus

Tantum erit illius nomen durabile quantum

Vere nova violae pallent albentque ligustra.

Ille ingens pastor facundo Aquavivius ore

Vivet et in nostris semper memorabitur arvis,

Cui tot sint quamvis formosa armanta gregesque

Nititur usque sequi doctae praecepta Minervae,

Praeferturque aliis ut populus alta myricis.

Perpetuo et vivet Cabalinius aurea cuius

Et rara est virtus sua tot qui armenta gregesque

Negligit et Phoebum et Musas veneratur amicas.

Illius et quovis caeduntur cortice facta.

Attius et vivet sacris notissimis antris

Quo cantante silent aurae fluviique residunt.

\section{Alphesiboeus}

Pastores hii equidem magni sunt optime Egene,

Pastorum decus et Latiis laus maxima sylvis.

Nuper si nescis nostris Aquavivius ille

Laeta libens ebuli concessit pascua bobus

Et virides myrtus et densas inter olivas

Nostra ubi vult demictat fistula carmen.

Et faciam, et mihi carmen erit, mihi numen et idem.

Praebuit et nobis taurum Cabalinius olim

Et nostrum vario dignatur munere Musam

Versibus et nostris Musa ipsa interserit illum.

Ante igitur tondent cythisum per inane capella

Et pascentur apes mediis thyma florida in undis

Quam nostram illorum subeant oblivia mentem.

\section{Egenus}

Quam bene tu nosti jucunde mihi Alphesiboee, Quam bene tu amborum placida pendebis ab aura.

Quare hii fata habeant semper ridentia, tuque

Spirantes illos, pereatque nocentibus astris

Plusius: ipse etiam Musa cum paupere vivam. 


\section{Traducción}

\section{Los pastores Mosticus, Egenus y Alphesiboeus ${ }^{25}$}

[Mosticus?] Según las murmuraciones del bosque, Plusius te desdeña y te odia, Egenus. Declara que eres muy perezoso y que vives de una forma reprensible. Quizás en algún momento le has causado algún daño.

[Egenus?] Admito que Plusius se considera rico con su choza y sus terrenos, que tiene abundancia de ovejas blancas como la nieve y de leche blanca, y que los dioses saben bien cómo consiguió esa riqueza. Aun así, es muy desgraciado al no saber tocar la flauta ni recitar poesía, y es de verdad desventurado al tener que vigilar, atender y trabajar tanto su hacienda con el fin de engrandecerla. Pero la choza que Plusius construyó con palos y muchas ramas es propensa a la destrucción provocada por fuegos y vientos; las tormentas pueden destruir sus anchos campos, y o bien el mal de ojo, la sarna o el contacto con alguna peste terrible puede reducir su ganado, como el tiempo infatigable, que la inclemencia del terrible cielo también puede perjudicar mis talentos o arruinar mi don de la poesía. El poder de la fortuna es grande, Mosticus, pero el de la virtud aún lo es más; ella nunca decepciona a sus amigos.

Mosticus: No sé nada sobre la fortuna ni sobre la virtud, pero conozco personalmente a Plusius. Es un hombre prominente y poderoso en nuestras colinas y a quien señalan los mancebos del campo, declarando: "Allí está ese hombre principal e importante, Plusius, a quien le pertenecen múltiples hectáreas de terreno para el maíz, que ni siquiera lo podrían cultivar todos los años cien bueyes, y que tiene viñas llenas de uvas productivas, $\mathrm{y}$ tantos bosques llenos de bellotas, que producen grandes cantidades de forraje, y fructíferos jardines regados por vivas fuentes de agua, que son sombreadas por bellos árboles y rodeados por bellos rosales. Tiene cien cabras en rebaños grandes, cien toros que compiten en rivalidad con sus cuernos, y pastorea mil cabritos que deambulan con sus madres. Siempre tiene queso fresco y abundancia de leche.

[Egenus?] Ruego que se desampare, esclavizado por la necesidad, que sea aplastado por la ansiedad; pero la pobreza, un estado más seguro, y una buena consciencia sobre la justicia, son mi condición. Para mí, la pobreza es una condición más enriquecedora, sólo si es está bien que me siente bajo un ancho árbol en el bosque elaborando mis versos. Que él se muestre entre los pinos y los olmos y que imponga nuevas leyes y regulaciones sobre los campesinos y sobre cualquier pastor a quien vea haciendo sacrificios favorables. Yo, entre los flexibles sauces y la humilde pradera, llamaré a

25 A la Profa Dra Gemma Puigvert Planagumà y al Prof Dr Pere Villalba Varneda, ambos de la Universitat Autònoma de Barcelona, debo mi primer y más sincero agradecimiento. Sus numerosas críticas, sugerencias y orientaciones contribuyeron sustancialmente a mejorar este trabajo. Sin embargo, cualquier error que permanezca es de mi única y exclusiva responsabilidad. 
Pan y a los sátiros para que escuchen mis canciones. Ruego que a la mesa de Pan nunca me falten alubias egipcias, ni leche ni fruta suculenta. Que tenga tomillo salvaje, ajo redolente y eneldo. Que crezcan los espárragos extensivamente en los salvajes surcos, y que haya castañas y agallas de roble. Que las aguas de una fuente cristalina y pura apaguen mi sed, y que la cháchara de las canciones de las aves y el murmullo de un arroyo que corre me traigan el dulce sueño entre las praderas pintadas de flores. Que yo esté contento con todos estos, y contento con mi flauta.

Mosticus: Créeme, Egenus, le concedes tanto a Plusius como lo hace la viña salvaje del bosque a las uvas cultivadas, tanto como la hiedra a las viñas, tanto como el humilde helecho a los sauces. Plusius es en todos los sentidos un hombre digno, y vivirá a través de los siglos.

Egenus: Su nombre durará como la violeta, que se marchita al principio de la primavera, y la alheña con sus blancas flores. Sin embargo, ese gran pastor, Aquavivius, el de la lengua elocuente, vivirá y siempre será recordado en nuestros campos. Aunque tenga bellísimos rebaños y ganados, sigue esforzándose a seguir los mandamientos de la docta Minerva y se le prefiere más que otros como el alto almo es preferido sobre el humilde tamarisco. Cabanilius también vivirá para siempre, cuya virtud es una cosa excepcional, el que desatiende sus numerosos rebaños y ganados y reverencia a Phoebus y a sus amigas, las musas. Sus hazañas se tallan en la corteza de cada árbol. Attius también vivirá, el que es conocido entre nuestras sagradas grutas, y que, cuando canta, se silencian las brisas y las aguas de los ríos se calman.

Alphesiboeus: estos sí que son ilustres pastores, mi querido Egenus. Y, recientemente, en el caso de que no lo sepas, Aquavivius, esa gloria de los pastores y el alarde más noble de los bosques del Latium, permitió con alegría que nuestros bueyes pastaran sobre su abundante saúco, y entre el verde mirto y las aceitunas abundantes mi dichosa flauta toca su canto por donde quiera. Así voy a continuar, y él me proporcionará un tema para mi canto, y será como un dios para mí. Cabalinius una vez me ofreció un toro, y honra a mi musa con varios regalos, y la musa misma lo pondrá en mis versos. Así que las cabras preferirán forrajear el trébol que crece en el aire, y las abejas favorecerán el tomillo en flor entre las olas del mar, antes que mi corazón se permita olvidar a estos hombres.

Egenus: Cuán bien los conoces, mi encantador Alphesiboeus, cuánto vas a disfrutar los serenos favores de los dos hombres. Así que siempre éstos disfruten la amena sonrisa de la fortuna, y que tú goces de su amparo. Que Plusius fallezca bajo estrellas perniciosas, y que viva yo con mi empobrecida musa.*

* Cláusula de divulgación: los autores han declarado que no existe ningún posible conflicto de intereses. 